\title{
Efektivitas Peran BPBD Dalam Upaya Rehabilitasi Dan Rekonstruksi Rumah Masyarakat Pasca Bencana Banjir Di Nagari Tanjung Sani Kabupaten Agam
}

\author{
Wahyu Rizana $^{1}$, Zikri Alhadi ${ }^{2}$ \\ 12) Jurusan Ilmu Administrasi Negara, Universitas Negeri Padang \\ wahyurizana@gmail.com,zikrialhadi@fis.unp.ac.id
}

\begin{tabular}{l}
\hline Article Info \\
Article history: \\
Article Received: June 082021 \\
Publication: July 072021 \\
\hline
\end{tabular}

Keywords:

Effectiveness, Role, Flood Disaster, Rehabilitation, and Reconstruction

\begin{abstract}
This study intends to find out the effectiveness of the role of BPBD in the rehabilitation and reconstruction of community houses after the flood disaster that occured in Agam Regency, namely Jorong Galapung Nagari Tanjung Sani Tanjung Raya District. This research is motivated by the constraints found in the rehabilitation and reconstruction efforts of community houses carried out by BPBD Agam Regency, namely inaccurate data or information obtained in the field, lack of community participation in socialization related to rehabilitation and reconstruction, $B P B D$ lacking in providing information regarding requirements and the timing of the rehabilitation and reconstruction, and lack of funds. In conducting this research, researcher used a qualitative approach using descriptive methods, then in determining the informants in this study the researcher used purposive sampling methods and techniques. Whereas in the data collection technique, researchers did it through interviews, observation and documentation. In testing the validity of the data, the researcher used the method triangulation technique. Meanwhile, in analyzing the data, the researcher used data reduction methods, data presentatin, and conclusions. The results of this study indicate that BPBD has been effective in carrying out the rehabilitation and reconstruction of community houses.
\end{abstract}

This is an open access article under the Lisensi Creative Commons Atribusi-BerbagiSerupa 4.0 Internasional

Corresponding Author:

Wahyu Rizana

Jurusan Ilmu Administrasi Negara, Universitas

Negeri Padang

Email: wahyurizana@gmail.com,

\section{PENDAHULUAN}

Negara Kesatuan Republik Indonesia merupakan suatu negara kepulauan terbesar di dunia dengan angka dan potensi bencana alam yang terbilang tinggi, serta merupakan negara kepulauan yang terdapat diantara 3 lempeng besaran yakni lempeng Eurasia, Pasifik, dan Indo Australia. Sehingga dapat menyebabkan memiliki tingkat kerawanan bencana gempa bumi dan letusan gunung api, serta tsunami. Selain itu, Indonesia yang posisinya berada pada wilayah atau daerah yang punya iklim tropis dengan 2 (dua) musim juga menyebabkan wilayah Indonesia rawan akan bencana tanah longsor, banjir, banjir bandang, serta abrasi ketika terjadi hujan dengan intensitas yang tinggiserta kekeringan dan kebakaran hutan saat musim kemarau yang panjang.

Bencana merupakan suatu peristiwa atau rangkaiannya yang dapat menjadi ancaman dan menjadi gangguan kehidupan masyarakat yang terjadi karena faktor manusia, faktor dari alam maupun dari faktor non alam sehingga dapat menyebabkan adanya korban jiwa, dampak psikologis, kerugian harta benda, dan kerusakan lingkungan (Pasal 1 Undang-Undang Nomor 24 Tahun 2007 Tentang Penanggulangan Bencana). Bencana alam merupakan suatu bencana yang akibat terjadinya serangkaian peristiwa alam yang diantaranya adalah angin topan, gempa 
bumi, tsunami, tanah longsor, banjir, gunung meletus, dan kekeringan. Bencana alam hampir selalu ada pada setiap musim hujan terjadi di Indonesia adalah banjir. Bencana banjir tersebut selalu dipengaruhi oleh dua faktor yaitu pertama faktor alam yang diantaranya adalah ketika terjadinya curah hujan diatas rata-rata, saat terjadi pasang surut air laut, yang kedua adalah faktor manusia diantaranya adalah penggunaan lahan pemukiman yang kurang tepat, pembabatan hutan, kurangnya daerah resapan air, dan penyumbatan akibat pembuangan sampah ke sungai.

Indonesia memiliki banyak provinsi, yang rawan terhadap bencana Salah satunya merupakan Provinsi Sumatera Barat. Yang mana Provinsi Sumatera Barat terdiri dari 19 Kabupaten, salah satunya adalah Kabupaten Agam yang terdiri dari kawasan suatu perbukitan dan pegunungan serta didominasi suatau kawasan hutan lindung berbasis ekonomi untuk pertanian (perkebunan suatau lahan kering serta hortikultura), namun termasuk kawasan yang rawan terhadap bencana yang memiliki sebaran dari potensi longsor, bahaya abrasi, tsunami, dan banjir. Hal ini dilihat berdasarkan data dari Badan Penanggulangan Bencana Daerah (BPBD) Kabupaten Agam terdapat 16 (enam belas) kecamatan di daerah Kabupaten Agam yang 11 (sebelas) diantaranya memiliki potensi bencana banjir saat terjadi hujan dengan intensitas tinggi. 11 kecamatan tersebut yakni Kecamatan Lubuk Basung dengan potensi banjir, Kecamatan Ampek Nagari dengan potensi banjir dan longsor, sementara untuk Kecamatan Tanjung Mutiara dengan potensi banjir dan longsor, Selanjutnya di tambaha dengan Kecamatan Matur dengan potensi banjir dan longsor, Kecamatan Palembayan dengan potensi longsor, Kemudian Kecamatan Ampek Koto berpotensi longsor, Untuk Kecamatan Malalak dengan potensi longsor, Kecamatan Palupuah berpotensi longsor, Kecamatan Baso dengan potensi bencana longsor, Kecamatan Canduang dengan potensi banjir, dan terakhir Kecmatan Tanjung Raya berpotensi banjir dan longsor (BPBD Kabupaten Agam).

Bencana banjir yang telah terjadi di Jorong Galapung pada tanggal 20 November 2021 disebabkan karena terjadinya hujan dengan intensitas yang tinggi. Penanggulangan bencana yang dilakukan oleh BPBD Kabupaten Agam ialah dengan melakukan pencegahan, tanggap darurat, rehabilitasi dan rekonstruksi. BPBD Kabupaten Agam melaksanakan rehabilitasi dan rekonstruksi rumah masyarakat yang bertujuan untuk melakukan pemulihan terhadap kondisi sosial dan kehidupan masyarakat. Pelaksanaan rehabilitasi dan rekonstruksi ini merupakan tugas BPBD, sesuai dengan Pasal 12 Peraturan Badan Nasional Penanggulangan Bencana (BNPB) Nomor 06 Tahun 2017 Tentang Penyelenggaraan Rehabilitasi dan Rekonstruksi Pasca Bencana, Badan Penanggulangan Bencana Daerah (BPBD) merupakan lembaga penanggung jawab pada proses pelaksanaan tindakan rehabilitasi dan rekonstruksi setelah terjadi bencana pada tingkat daerah. Sehingga berdasarkan hal tersebut peneliti melakukan penelitian mengenai efektivitas peran BPBD dalam upaya rehabilitasi dan rekonstruksi rumah masyarakat setelah terjadi bencana banjir di suatu Jorong Galapung Nagari Tanjung Sani.

\section{TINJAUAN PUSTAKA}

\subsection{Konsep Efektivitas}

Menurut Ndraha 2003 dalam (Muhammad Sawir, 2020:130) efektivitas merupakan tingkat keberhasilan pencapaian tujuan (target). Selanjutnya Siagian 2001 dalam (Aswar Annas, 2017:13) menyatakan efektivitas sebagai suatu pemanfaatan sarana, prasarana, dan sumber daya dalam jumlah tertentu dan telah ditetapkan sebelumnya secara sadar dalam rangka menghasilkan barang ataupun jasa. James L. Gibson dkk (Pasolong, 2013:4) berpendapat efektivitas merupakan suatu bentuk peraihan terhadap saasaran suatu upaya milik bersama yang telah dilakukan. Sebuah organisasi dapat diketahui efektif jika organisasi tersebut bisa mencapai tujuannya serta mewujudkan setiap nilai sesuai dengan visi yang telah ditetapkan dalam organisasi. Duncan (dalam Maulana Mufis, 2016) berpendapat bahwa untuk mengukur efektivitas dapat memakai indikator beberapa indikator diantaranya adalah :

\section{a. Pencapaian Tujuan}

Sebuah pencapaian adalah seluruh upaya yang dilakukan dalam proses pencapaian 
tujuan yang dilihat sebagai suatu proses. Agar pencapaian tujuan hingga akhir bisa terjamin,maka sebuah tujuan harus jelas, memiliki hasil yang dapat diukur, ada target, dan mempunyai batas waktu tertentu

\section{b. Kemampuan Integrasi}

Integrasi merupakan pengukuran terhadap kemampuan yang dimiliki oelh suatu organisasi dalam melakukan sosialisasi dan komunikasi dengan beberapa organisasi lainnya, dengan kata lain integrasi dalam hal ini memiliki keterkaitan dengan proses sosialisasi yang dilakukan organisasi tersebut.

\section{c. Kemampuan Adaptasi}

Adaptasi merupakan kemampuan yang dimiliki oleh suatu organisasi dalam menyesuaikan diri dengan kondisi lingkungan disekitarnya yang mempunyai kaitan dengan kesesuaian antara pelaksanaan program organisasi dengan keadaan atau kondisi yang ada dilapangan.

\subsection{Konsep Peran}

Menurut Raho (2016) dalam Zikri Alhadi (2018) peran merupakansesuatu yang diharapkan oleh masyarakat dari sebuah tingkah laku seorang individu yang mempunyai status ataupun posisi tertentu di tengah-tengah masyarakat. Definisi peran menurut pendapat Abu Ahmadi (1982:74) dalam Muhammad Ali dkk (2019) merupakan kompleks harapan dari manusia terhadap bagaimana cara dari seseorang harus bersikap dan bertindak pada saat-saat tertentu sesuai dengan status serta fung sosial yang dimilikinya.

\subsection{Konsep Bencana Banjir}

Menurut Khambali (2017:4) dalam Manajemen Penanggulangan Bencana banjir merupakan bencana disebabkan akibat adanya curah hujan yang tinggi dan tidak mampu ditampung oleh saluran-saluran irigasi atau tempat pembuangan air yang memadai sehingga mengakibatkan air meluap dan merendam daerah yang tidak diinginkan. Selain itu, banjir tersebut juga dapat terjadi dikarenakan rusaknya sistem-sistem aliran air yang tersedia sehingga wilayah yang lebih rendah akan terdampak banjir kiriman. Sedangkan Menurut Paimin dkk (2009:2) dalam Siska Kania Oktapian dkk (2018) banjir adalah kondisi dimana jumlah aliran air secara relatif lebih besar daripada biasanya dikarenakan turunnya hujan di hulu atau tempat- tempat tertentu dalam waktu yang lama sehingga menyebabkan debit air melimpah dan tidak dapat ditampung lagi oleh aliran sungai yang tersedia, dan mengakibatkan terjadinya pelimpahan air dan menggenangi setiap daerah disekitarnya yang lebih rendah.

\subsection{Konsep Rehabilitasi dan Rekonstruksi}

Menurut Sri Wahyuni (2020) rehabilitasi adalah pemulihan ataupun perbaikan daerah bencana agar dapat kembali pada kondisi atau fungsi seperti sebelum terjadi bencana. Penyelenggaraan rehabilitasi dilaksanakan berdasarkan Pasal 8 Peraturan Badan Nasional Penanggulangan Bencana (BNPB) Nomor 06 Tahun 2017 Tentang Penyelenggaraan Rehabilitasi dan Rekonstruksi Pasca Bencana.

Sedangkan untuk reksonstruksi menurut Rohmat (2019:38) dalam Penanggulangan Bencana Alam Klimatologis, rekonstruksi adalah suatu kegiatan membangun kembali secara keseluruhan sarana serta prasarana termasuk rumah masyarakat. Tujuan atau sasaran paling utama dari rekonstruksi adalah mengembangkan kegiatan perekonomian, sosial dan budaya, membangkitkan partisipasi masyarakat pada setiap aspek kehidupan, serta tegaknya hukum dan ketertiban di wilayah pasca bencana. Kegiatan rekonstruksi adalah tanggung jawab dari pemerintah daerah yang dilanda bencana, dan pemerintah daerah tersebut perlu membuat rencana rekonstruksi yang juga merupakan suatu kesatuan dengan rencana pelaksanaan rehabilitasi.

\section{METODE PENELITIAN}

Jenis penelitian yang digunakan peneliti, dalam penelitian ini yaitu penelitian kualitatif dengan menggunakan suatu metode deskriptif. Untuk Penelitian dilakukan di Lubuk Basung 
tepatnya di Badan Penanggulangan Bencana Daerah (BPBD) Kabupaten Agam Narasumber atau informan penelitan ini dilakukan dengan menggunakan suatu teknik purposive sampling. Melalui Teknik pengumpulan data, peneliti menggunakan suatu teknik wawancara, teknik observasi, serta teknik studi dokumentasi. Sedangkan untuk teknik yang dipakai untuk analisis suatu data yang peneliti gunakan yaitu melalui reduksi data, melalui penyajian data, serta melalui verifikasi atau kesimpulan.

\section{HASIL PENELITIAN DAN PEMBAHASAN}

Bencana merupakan suatu serangkaian peristiwa yang dapat mengganggu dan menjadi ancaman bagi kehidupan suatu masyarakat, biasanya akibat faktor dari manusia, faktor dari alam, maupun faktor dari non alam. Sehingga dapat menyebabkan adanya korban jiwa, kemudian terdapatnya kerugian harta benda, serta terdapatnya kerusakan lingkungan, serta terdapat gangguan psikologis (Pasal 1 Undang-Undang Nomor 24 Tahun 2007 Tentang Penanggulangan Bencana). Indonesia merupakan suatu negara yang rawan terhadap bencanan di dunia. Sehingga telah mempunyai persiapan untuk menghadapi bencana-bencana yang akan terjadi, yakni dengan membentuk organisasi atau lembaga yang khusus melakukan persiapan dan membuat kebijakan untuk melakukan penanggulangan bencana yang mungkin terjadi kapan saja. Penyelenggaraan atau pelaksanaan penanggulangan bencana adalah tanggung jawab dari semua lapisan masyarakat, baik itu pemerintah pusat ataupun daerah, pihak swasta, maupun masyarakat umum atau individu, akan tetapi juga diperlukan organisasi atau lembaga yang berfungsi sebagai wadah untuk menyalurkan dan mengkoordinasi seluruh sumber daya yang tersedia agar bisa digunakan semaksimal mungkin. Organisasi tersebut adalah Badan Nasional Penanggulangan Bencana (BNPB) pada tingkat pusat, serta Badan Penanggulangan Bencana Daerah (BPBD) pada tingkat daerah provonsi dan daerah kabupaten.

Provinsi Sumatera Barat yang memiliki 19 Kabupaten salah satunya adalah Kabupaten Agam yang termasuk kawasan yang rawan akan bencana seperti tsunami, abrasi, banjir, dan tanah longsor. Ketika terjadi bencana pada suatu daerah, maka perlu dilakukan tindakan penanggulangan bencana. Terutama pada bencana banjir yang telah terjadi di Jorong Galapung Nagari Tanjung Sani Kecamatan Tanjung Raya Kabupaten Agam. Pada bencana banjir yang telah terjadi di Jorong Galapung tersebut, Badan Penanggulangan Bencana Daerah (BPBD) Kabupaten Agam telah melakukan tindakan penanggulangan bencana yang dimulai dari tahapan pra atau sebelum terjadi bencana, tahap tanggap darurat, dan pasca atau setelah terjadi bencana.

Pada bencana banjir yang terjadi di Jorong Galapung Nagari Tanjung Sani Kecamatan Tanjung Raya Kabupaten Agam, BPBD Kabupaten Agam mulai melakukan suatu tindakan penanggulangan bencana mulai dari tahap pra bencana, dan tahap tanggap darurat, serta pada tahap pasca bencana. Badan Penanggulangan Bencana Daerah (BPBD) Kabupaten Agam melaksanakan tindakan rehabilitasi dan rekonstruksi terhadap rumah masyarakat korban banjir. Proses rehabilitasi dan rekonstruksi setelah bencana dilakukan dengan tujuan agar tercipta pemulihan kondisi kehidupan masyarakat secara fisik, mental, ekonomi, sosial dan budaya. Badan Penanggulangan Bencana Daerah (BPBD) Kabupaten Agam mempunyai dalam melakukan rehabilitasi dan rekonstruksi rumah masyarakat korban banjir karena sudah menjadi tugas dan tanggung jawab BPBD sesuai dengan Peraturan Badan Nasional Penanggulangan Bencana (BNPB) Nomor 06 Tahun 2017 Tentang Penyelenggaraan Rehabilitasi dan Rekonstruksi Pasca Bencana. Berdasarkan permasalahan yang telah penulis temukan di lapangan, maka perlu diketahui bagaimana efektivitas peran BPBD dalam melakukan rehabilitasi dan rekonstruksi rumah masyarakat pasca banjir di Jorong Galapung Nagari Tanjung Sani. Untuk mengetahui efektivitas peran BPBD peneliti menggunakan indikator efektivitas menurut Duncan dengan indikator sebagai berikut :

\section{a. Pencapaian Tujuan}

Suatu organisasi mempunyai tujuan yang sudah ditentukan harus dicapai berdasarkan rencana atau target yang sudah diputuskan sehingga setiap kegiatan organisasi dapat berjalan secara terarah. Pencapaian tujuan mempunyai beberapa tolak ukur diantaranya adalah sebuah 
tujuan/target yang jelas dan mempunyai batas waktu tertentu. Organisasi dapat dikatakan efektif apabila tujuan yang dicapai memiliki kesesuaian dengan rencana yang telah ditetapkan baik terkait waktu pelaksanaan pencapaian tujuan maupun ketepatan sasaran/ tujuan. Efektivitas peran BPBD dalam rehabilitasi dan rekonstruksi rumah masyarakat pasca atau setelah bencana banjir di Jorong Galapung Nagari Tanjung Sani Kecamatan Tanjung Raya Kabupaten Agam dapat diukur melalui sejauh mana pencapaian tujuan dari pelaksanaan rehabilitasi dan rekonstruksi rumah masyarakat itu sendiri, ketetapatan sasaran, dan batas waktu yang dibutuhkan oleh BPBD untuk melakukannya.

BPBD Kabupaten Agam telah melaksanakan rehabilitasi dan rekonstruksi terhadap 14 rumah masyarakat yang telah terdampak bencana banjir. Dimana BPBD Kabupaten Agam melakukan perbaikan rumah masyarakat yang mengalami kerusakan ringan, sedang maupun kerusakan berat. Proses rehabilitasi dan rekonstruksi dilakukan dengan cepat serta sesuai dengan target atau batas waktu yang sudah ditetapkan, untuk rehabilitasi dan rekonstruksi BPBD Kabupaten Agam melakukannya dalam jangka waktu kurang lebih 12 bulan.

\section{b. Integrasi}

Integrasi dapat diartikan sebagai pengukuran terhadap tingkatan kemampuan sebuah organisasi dalam melakukan sosialisasi serta komunikasi dengan masyarakat atau beberapa organisasi lainnya, dengan kata lain integrasi dalam hal ini berkaitan dengan proses sosialisasi organisasi tersebut dalam rangka membentuk kerjasama atau koordinasi. Integrasi tentunya diperlukan dalam melakukan rehabilitasi dan rekonstruksi rumah masyarakat, sehingga BPBD Kabupaten Agam perlu melibatkan masyarakat serta lembaga/organisasi lain untuk mempercepat pelaksanaan proses rehabilitasi dan rekonstruksi rumah masyarakat.

Dalam penelitian ini, integrasi dijadikan sebagai salah satu indikator untuk mengukur efektivitas peran BPBD melalui umpan balik (feedback) dari sosialisasi yang telah dilakukan oleh BPBD dengan masyarakat maupun organisasi atau lembaga lain agar terbentuk kerjasama atau koordinasi dalam proses rehabilitasi dan rekonstruksi rumah masyarakat pasca banjir di Jorong Galapung Nagari Tanjung Sani Kecamatan Tanjung Raya Kabupaten Agam. Kegiatan yang dilakukan oleh BPBD Kabupaten Agam dalam bencana banjir yang terjadi di Jorong Galapung adalah Tim Jitu Pasna BPBD Kabupaten Agam melakukan identifikasi data kerusakan pasca bencana, kemudian melakukan rehabilitasi dan rekonstruksi terhadap rumah masyarakat, setelah itu melaksanakan monitoring atau pemantauan dan evaluasi pada pelaksanaan rehabilitasi dan rekonstruksi.

Tim Jitu Pasna dan Wali Nagari beserta LSM (Lembaga Swadaya Masyarakat) membentuk koordinasi saat melakukan identifikasi kerusakan pasca bencana di lokasi bencana. Sebelum dilaksanakan tahapan rehabilitasi dan rekonstruksi BPBD juga memberikan sosialisasi terkait pelaksanaan rehabilitasi dan rekonstruksi kepada masyarakat yang rumahnya terdampak bencana banjir. BPBD Kabupaten Agam telah melakukan kerjasama dan sosialisasi terkait proses rehabilitasi dan rekonstruksi 14 rumah masyarakat yang rusak akibat bencana banjir. Dalam melakukan rehabilitasi dan rekonstruksi BPBD menjalin komunikasi untuk membentuk kerjasama yang terintegrasi antara BPBD dengan pemerintah daerah pada tingkat jorong, nagari, dan kecamatan di wilayah bencana.

\section{c. Adaptasi}

Adaptasi merupakan suatu kemampuan yang dimiliki organisasi untuk menyesuaikan diri dengan kondisi lingkungan disekitarnya yang memiliki hubungan atau kaitan dengan kecocokan atau kesesuaian pelaksanaan program dengan kondisi yang terdapat di lapangan. Berdasarkan hal tersebut maka indikator adaptasi bisa digunakan sebagai tolak ukur untuk mengetahui efektivitas peran BPBD dalam rehabilitasi dan rekonstruksi rumah masyarakat.

Pada penelitian ini BPBD Kabupaten Agam dapat dikatakan efektif apabila terdapat kesesuaian program BPBD saat melakukan rehabilitasi dan rekonstruksi rumah masyarakat dengan tepat sasaran. Program rehabilitasi yang dilakukan oleh BPBD Kabupaten Agam adalah memberikan dana bantuan kepada rumah masyarakat serta melakukan rekonstruksi dengan memanfaatkan dana yang diterima semaksimal mungkin. Dalam melaksanakan 
rehabilitasi dan rekonstruksi, BPBD Kabupaten Agam melakukan pengkajian dan analisis yang tepat agar setiap masyarakat yang rumahnya mengalami kerusakan memperoleh tindakan dan bantuan dana yang sesuai.

\section{PENUTUP}

Berdasarkan hasil temuan yang telah dibahas dalam pembahasan bahwa Efektivitas peran Badan Penanggulangan Bencana Daerah (BPBD) Kabupaten Agam dalam upaya rehabilitasi dan rekonstruksi rumah masyarakat pada saat setelah terjadi bencana banjir di Jorong Galapung Nagari Tanjung Sani Kecamatan Tanjung Raya Kabupaten Agam dapat disimpulkan bahwa rehabilitasi dan rekonstruksi rumah masyarakat yang dilakukan oleh BPBD Kabupaten Agam sudah efektif, hal tersebut dapat diketahui dari faktor pencapaian tujuan, integrasi, dan adaptasi yang dilakukan oleh BPBD pada proses pelaksanaan rehabilitasi dan rekonstruksi rumah masyarakat. Yang pertama adalah dari segi pencapian tujuan yang dilakukan oleh BPBD Kabupaten Agam dalam pelaksanaan rehabilitasi dan rekonstruksi rumah masyarakat berjalan dengan baik. Hasil temuan penelitian menunjukkan bahwa BPBD Kabupaten Agam telah melaksanakan rehabilitasi dan rekonstruksi terhadap 14 rumah masyarakat yang terdampak bencana banjir dengan tindakan rehabilitasi sebanyak 9 rumah dan rekonstruksi sebanyak 5 rumah. Dimana BPBD Kabupaten Agam melakukan perbaikan rumah masyarakat yang mengalami kerusakan ringan, sedang maupun kerusakan berat. Proses rehabilitasi dan rekonstruksi dilakukan dengan cepat serta sesuai atau cocok dengan batas waktu yang sudah ditetapkan, untuk rehabilitasi dan rekonstruksi BPBD melakukannya dalam jangka waktu kurang lebih 12 bulan. Selanjutnya yang kedua adalah integrasi BPBD Kabupaten Agam dalam pelaksanaan rehabilitasi dan rekonstruksi rumah masyarakat.

Berdasarkan hasil temuan penelitian diketahui bahwa integrasi yang dilakukan oleh BPBD Kabupaten Agam dalam melakukan rehabilitasi dan rekonstruksi rumah masyarakat adalah berkoordinasi dan berkomunikasi dengan jajaran pemerintahan tingkat jorong, nagari, dan kecamatan serta sosialisasi kepada masyarakat terdampak bencana banjir. Yang ketiga adalah adaptasi BPBD Kabupaten Agam dalam pelaksanaan rehabilitasi dan rekonstruksi rumah masyarakat. Adaptasi tersebut berkaitan dengan kesesuaian program rehabilitasi dan rekonstruksi yang dilakukan oleh BPBD Kabupaten Agam dilapangan. Berdasarkan hasil temuan penelitian, dapat dilihat bahwa rehabilitasi yang dilakukan oleh BPBD Kabupaten Agam sudah baik, akan tetapi rekonstruksi yang dilakukan oleh BPBD Kabupaten Agam masih terdapat kendala yaitu lokasi rumah yang jauh dan akses jalan yang sulit, serta tidak adanya mata pencarian bagi masyarakat yang menerima program rekonstruksi.

\section{DAFTAR KEPUSTAKAAN}

Adiyoso, Wignyo. 2018. Manajemen Bencana Pengantar dan Isu-isu Strategis. Jakarta : Bumi Aksara

Aini, Nur dkk. 2018. Efektivitas Program Desa Tangguh Bencana di Desa Sirnoboyo Kecamatan Pacitan Kabupaten Pacitan Tahun 2017. Jurnal Mahasiswa Ilmu Pemerintahan. Volume 03 Nomor 02

Alhadi, Zikri. 2014. Kesiapan Jalur dan Lokasi Evakuasi Publik Menghadapi Resiko Bencana Gempa dan Tsunami di Kota Padang. Jurnal Humanis Volume XIII Nomor 1 Tahun 2014

Alhadi, Zikri. 2018. Faktor yang Mempengaruhi Peranan Kelompok Siaga Bencana Untuk Mewujudkan Kesiapsiagaan Masyarakat di Kota Padang. Jurnal Ilmu Administrasi Publik. Volume 1 Nomor 1 Tahun 2018

Ali, Muhammad dkk. 2019. Peran Pemerintah Daerah Terhadap Penyelesaian Permasalahan Korban Bencana Gempa (Studi di Dinas Sosial Kabupaten Lombok Barat). Jurnal Ilmu Administrasi Publi. Volume 7 Nomor 2 September 2019, Halaman 153-166

Annas, Aswar. 2017. Interaksi Pengambilan Keputusan dan Evaluasi Kebijakan. Jakarta : Celebes Media Perkasa 
Khambali. 2017. Manajemen Penanggulangan Bencana. Yogyakarta : CV. Andi Moleong, Lexy J. 2009. Metode Penelitian Kualitatif. Bandung : PT. Remaja Rosdakarya Mughron, Maulana Mufis dkk. 2016. Efektivitas Badang Penanggulangan Bencana Daerah (BPBD) dalam Pelaksanaan Program Kelurahan Siaga Bencana di Kota Semarang. Journal Of Public Policy and Management. Volume 5 Nomor 1 Tahun 2016

Pasolong, Harbani. 2013. Teori Administrasi Publik. Bandung : Alfabeta

Peraturan Badan Nasional Penanggulangan Bencana (BNPB) Republik Indonesia Nomor 06

Tahun 2017 Tentang Penyelenggaraan Rehabilitasi dan Rekonstruksi Pasca Bencana

Rohmat. 2019. Penanggulangan Bencana Alam Klimatologis. Penerbit : Duta

Sawir, Muhammad. 2020. Birokrasi Pelayanan Publik Konsep, Teori, dan Aplikasi. Yogyakarta: Deepublish

Undang-Undang No. 24 Tahun 2007 Tentang Penanggulangan Bencana

Wahyuni, Sri. 2020. Peran Dinas Perpustakaan dan Kearsipan Aceh dalam Rehabilitasi dan Rekonstruksi Pembangunan Perpustakaan Pasca Tsunami Aceh. Adabiya Volume 22 Nomor 1 Februari 2020 